\title{
Análise de competitividade em clusters de negócio: uma consolidação de parâmetros
}

\author{
Ana Cláudia Azevedo \\ Universidade Federal de Viçosa - Viçosa - MG - Brasil \\ ORCID: orcid.org/0000-0001-8141-9265 \\ Cristina Espinheira Costa Pereira \\ FAM Centro Universitário e Universidade Ibirapuera - São Paulo - SP - \\ Brasil \\ ORCID: orcid.org/0000-0001-7622-9803 \\ Keysa Manuela Cunha de Mascena \\ Universidade de Fortaleza - Fortaleza - CE - Brasil \\ ORCID: orcid.org/0000-0002-0844-500X
}

\begin{abstract}
Resumo
Compreender a competitividade dos clusters requer uma análise para além da concentração geográfica, contemplando outros fatores determinantes desta competitividade. No entanto, não existe consenso em relação a estes fatores e, consequentemente, não há uma consolidação das métricas para operacionalizá-los, constituindo um entrave para realização de estudos aplicados a esses objetos. Diante disso, o objetivo deste estudo foi identificar, comparar e consolidar modelos empregados na análise da competitividade de clusters a partir de estudos nacionais. Para tanto, realizou-se uma revisão sistemática em artigos da base SPELL publicados entre 2000 e 2016. Identificou-se a utilização de dezessete modelos, contemplando vinte fatores de competitividade e, para cada fator, consolidou-se uma métrica e seu referencial de avaliação. Os fatores de competitividade mais relevantes foram a cooperação, e, abrangência de negócios viáveis e relevantes. A contribuição desta pesquisa é predominantemente metodológica fundamentada no fornecimento de parâmetros consolidados para análise da competitividade de clusters de negócios. Palavras-chave: Clusters. Competitividade. Modelos. Parâmetros. Métricas
\end{abstract}

\section{Analysis of competitiveness in business clusters: a consolidation of parameters}

\section{Abstract}

Understanding the competitiveness of clusters requires analysis beyond geographic concentration, contemplating other factors determining this competitiveness. However, there is no consensus regarding these factors and, consequently, there is 
no consolidation of the metrics to operationalize them, constituting an obstacle to carrying out studies applied to these objects. Therefore, the objective of this study was to identify, compare, and consolidate models used in the analysis of the cluster's competitiveness from national studies. A systematic review was carried out on SPELL articles published between 2000 and 2016. We identified the use of seventeen models, including twenty competitiveness factors, and for each factor, a metric and its evaluation framework. The most relevant competitiveness factors were cooperation and the coverage of viable and relevant businesses. The contribution of this research is predominantly methodological based on the provision of consolidated parameters to analyze the competitiveness of business clusters.

Keywords: Clusters. Competitiveness. Models. Parameters. Metrics.

\section{Análisis de competitividad en clusters de negocio: una consolidación de parámetros}

\section{Resumen}

Comprender la competitividad de los clusters requiere un análisis más allá de la concentración geográfica, contemplando otros factores determinantes de esta competitividad. Sin embargo, no existe consenso con relación a estos factores y, consecuentemente, no hay una consolidación de las métricas para operacionalizarlos, constituyendo un obstáculo para la realización de estudios aplicados a esos objetos. El objetivo de este estudio fue identificar, comparar y consolidar modelos empleados en el análisis de la competitividad de clusters a partir de estudios nacionales. Para ello, se realizó una revisión sistemática en artículos de la base SPELL publicados entre 2000 y 2016. Se identificó la utilización de diecisiete modelos, contemplando veinte factores de competitividad y, para cada factor, se consolidó una métrica y su referencia de evaluación. Los factores de competitividad más relevantes fueron la cooperación, y el alcance de negocios viables y relevantes. La contribución de esta investigación es predominantemente metodológica fundamentada en el suministro de parámetros consolidados para análisis de la competitividad de clusters de negocios.

Palabras clave: Clusters. Competitividad. Modelos. Parámetros. Métricas.

\section{Introdução}

Clusters são agrupamentos de empresas e instituições correlatas, geograficamente concentradas, vinculadas por elementos comuns e complementares, que competem, mas também cooperam entre si (PORTER, 1999). A dinâmica destes arranjos empresariais envolve ações conjuntas em áreas diversificadas, como: recursos humanos, pesquisa e desenvolvimento, marketing, internacionalização e outros, inserindo na agenda estratégica questões relevantes para obtenção de vantagens competitivas (DI SERIO, 2007).

Estes agrupamentos promovem o aumento da competitividade de empresas e regiões (MARINI; CORREA NETO, 2018), dada as amplamente reconhecidas economias de localização e urbanização (MOULAERT; DJELLAL, 1995) ou as 
economias de aglomeração (PORTER, 1998). Nesse sentido, a avaliação da competitividade dos clusters é uma questão discutida na literatura (SKOKAN; ZOTYKOVÁ, 2014). Esta competitividade, no entanto, deve ser analisada na perspectiva supra empresarial, considerando a ótica sistêmica de que o todo é maior que a soma das partes (ZACCARELLI et al., 2008; TELLES et al., 2012). Dessa forma, empresas que atuam em clusters alcançam ganhos coletivos que ampliam o seu poder de competição em relação às empresas que atuam isoladas (PORTER, 1990; SKOKAN; ZOTYKOVÁ, 2014).

A competitividade de um cluster não se dá apenas pela proximidade das empresas que o compõe, mas também em função de outros aspectos econômicos e sociais inerentes à interação interorganizacional (JUSTEN; PAES-DE-SOUZA, 2017). Em função de sua natureza complexa, compreender a competitividade dos clusters requer uma análise que ultrapasse o aspecto da concentração geográfica, contemplando outras evidências, fatores ou fundamentos que favoreçam esta competitividade (ZACCARELLI et al., 2008). Outro aspecto tão, ou mais importante, é o estabelecimento de parâmetros que permitam mensurar essa competitividade (SHAFAEI, 2009).

Neste contexto, ao revisitar a literatura, verifica-se a existência de modelos teóricos diversos, reconhecidos por viabilizar a avaliação e o dimensionamento do nível de competitividade de um cluster, a exemplo de Marshall (1890), Porter (1990, 1998), Schmitz (1992), UK Department (1999), Zaccarelli et al. (2008) e Kamath, Agrawal e Chase (2012). Contudo, uma consequência dessa diversidade de modelos é que não existe um consenso em relação aos fatores necessários para avaliar a competitividade em clusters e, consequentemente, não há uma consolidação das métricas utilizadas para operacionalizar estes modelos (PEREIRA et al., 2014), o que constitui uma limitação para os estudos empíricos que se propõem a analisar o nível de competitividade destes arranjos organizacionais.

Apesar da inconsistencia observada, cumpre destacar que em geral os clusters não são homogêneos (DE MARCHI; GRANDINETTI, 2014). He e Fallah (2011, p. 945) argumentam que "indústrias diferentes tendem a suportar tipos diferentes de clusters. Em outras palavras, um cluster individual é, em certa medida, moldado pelo grupo industrial ao qual pertence". Logo, as formas de analisar e dimensionar a competitividade em tais arranjos mostram-se condicionadas as características dos mesmos, sobretudo as que envolvem a intensidade tecnológica e a natureza das atividades. Ainda assim, argumenta-se que consideradas tais particularidades é possível traçar denominadores comuns que permitam a edificação e o avanço das pesquisas no escopo do dimensionamento da competitividade de tais arranjos.

Isto posto, o objetivo deste estudo é identificar, comparar e consolidar modelos empregados na análise da competitividade dos clusters a partir de estudos nacionais. Este objetivo desdobra-se em objetivos secundários, quais sejam: (i) levantar a produção nacional acerca da competitividade em clusters (ii) identificar os modelos empíricos e teórico-empíricos utilizados para viabilizar esta análise; (iii) identificar os principais fatores que constituem estes modelos; (iv) inventariar e comparar as métricas adotadas com a função de operacionalizar os modelos.

Muitos estudos, a exemplo de Siqueira, Gerth e Boaventura (2011), Pereira et al. (2013), Tiscoski e Morais (2013) e Jacoski et al. (2014), dedicaram-se a revisar o tema de competitividade em clusters. Porém, o diferencial proposto por este artigo 
consiste em inventariar modelos e métricas que são empregadas para avaliar tais níveis de competitividade, apresentando um panorama contemporâneo das pesquisas nacionais nessa área. Assim, espera-se contribuir para o alinhamento e consolidação destas métricas, favorecendo a efetiva mensuração da capacidade competitiva dos clusters e o desenvolvimento de futuras pesquisas envolvendo esta temática.

\section{Fundamentação Teórica}

Para entender os fatores que influenciam a competitividade de clusters, a fundamentação teórica conceitua clusters e apresenta as abordagens teóricas que fundamentam o estudo desta relação. Em seguida, são apresentados os conceitos associados à avaliação da competitividade de clusters.

\subsection{Clusters}

Uma das primeiras menções às aglomerações de empresas de que se tem evidências na literatura decorre da obra Principles of Economics publicada por Alfred Marshall em 1890. Em sua obra, Marshall refere-se aos ganhos gerados por fatores locacionais decorrentes de condições geográficas e físicas e também da proximidade do mercado consumidor (MARSHALL, 1890).

Ao enfatizar a dimensão territorial, Marshall (1890) destacou que as vantagens da produção em escala são mais eficientes a partir da concentração espacial de um grande número de empresas em um lócus específico. Para o autor, essa concentração provocaria o equacionamento da dinâmica de competição e cooperação entre as firmas, aumentando a eficiência coletiva. Contudo, foi a partir da obra The Competitive Advantage of Nations publicada por Michael Porter em 1990, que tais aglomerações, denominadas de clusters, efetivamente alcançaram reconhecimento em âmbito acadêmico e gerencial.

Ao longo do seu desenvolvimento, as formas de aglomerações de empresas foram analisadas por diversos pesquisadores, em diferentes contextos históricos e geográficos, inclusive com pressupostos epistemológicos distintos (SACOMANO NETO; PAULILLO, 2012). Newlands (2003) compilou esses conceitos dividindo-os em cinco abordagens teóricas: Teoria da Aglomeração, Custos de Transação, Especialização Flexível, Millieux Inovador e Economia Institucional e Evolucionária.

$\mathrm{Na}$ Teoria da Aglomeração, clusters são percebidos como conjuntos de empresas, conectadas através de relações com o mercado, e não por colaboração deliberada; já a abordagem do Custos de Transação prevê que a conexão das empresas através de operações e mercados, e a partilha de informações por intermédio de confiança, poderia minimizar os custos de transações agregando valor às atividades das empresas do cluster. Na abordagem da Especialização Flexível consideram-se as empresas do cluster como interdependentes e capazes de obter (por intermédio de confiança) ganhos de transferência de conhecimentos para além das transações formais. O cluster visto como um processo coletivo de aprendizado decorrente de mão-de-obra qualificada, interação e mobilidade remetem à abordagem do Millieux inovador. E por fim, na abordagem da Economia 
Institucional e Evolucionária, clusters refletem o impacto de decisões passadas e a influência e crescimento de instituições de apoio (NEWLANDS, 2003).

Em função das diferentes abordagens, a terminologia relativa a aglomerações de empresas é bastante controversa. Conforme mencionam Lastres e Cassiolato (2005), existem outros termos inerentes aos estudos de aglomerações além dos referidos clusters, tais como: cadeia produtiva, arranjo produtivo local, distritos industriais, millieux inovador, polos, parques científicos e tecnológicos, redes de empresas e outros. Neste estudo, em função do posicionamento adotado, emprega-se o termo cluster como representativo de todas estas variações.

Nas últimas décadas, as pesquisas sobre clusters acumularam um corpo crescente de literatura que atribui à concentração geográfica de determinada indústria, ou setor, certos mecanismos que contribuem para o desenvolvimento da região: o mecanismo fundador e o da sobrevivência. De acordo com o mecanismo fundador, dada à promessa de ganhos econômicos exclusivos de co-localização, investidores estão mais propensos a fundar seus negócios dentro de clusters, além disso, quando incorporados em redes sociais locais são mais propensos a observar e explorar oportunidades de investimento (WANG et al., 2014).

Por outro lado, segundo o mecanismo de sobrevivência, empresas localizadas próximas geograficamente obtêm ganhos econômicos através da partilha de recursos comuns, como vantagens naturais (HOOVER, 1948), mão-deobra qualificada, fornecedores especializados e transbordamentos de conhecimento (KRUGMAN, 1991). Estas vantagens regionais determinam certos fatores que permitem às empresas em cluster um melhor desempenho e, assim, sobreviver por mais tempo do que as menos aglomeradas.

\subsection{Análise da competitividade de clusters}

A proposição de que empresas localizadas em clusters de negócios alcançam melhor desempenho competitivo em relação a empresas isoladas está retratada na literatura por estudos como Porter (1990, 1999); Schimitz (1992), Zaccarelli (2000) e Zaccarelli et al. (2008). Estes estudos defendem que os clusters representam uma forma de obter competitividade e sobreviver no mundo globalizado, através da redução de custos de produção, ampliação da escala produtiva e das dimensões de mercado, promoção de inovações e demais ações compartilhadas.

Os clusters expõem as empresas a fatores como: pools de mão-de-obra qualificada, fornecedores especializados, potenciais spillovers de conhecimento entre empresas, dentre outros. A soma destes fatores pode gerar economias de aglomeração (benefícios observados no desempenho das empresas co-localizadas e que excedem o valor dos insumos consumidos), que dão às empresas uma oportunidade para desenvolverem vantagem competitiva (ALCÁCER; CHUNG, 2014).

Contudo, a formação de clusters não garante crescimento e competitividade ou ganhos econômicos de forma automática, embora seja um facilitador para se atingir tais objetivos (SCHMITZ, 1997). É importante considerar que diante da gama de fatores que envolvem um cluster e seu potencial competitivo é necessário analisar o conjunto destes fatores, também chamados de fundamentos, que se constituem em evidências observáveis da vantagem competitiva deste sistema supra empresarial (ZACCARELLI et al., 2008). 
Nesta vertente, muitos estudos se propuseram a analisar os clusters teórica e empiricamente - buscando identificar características que conjuntamente fossem capazes de prover o desenvolvimento destes arranjos, garantindo maior competitividade aos mesmos, à exemplo de Marshall (1890), Porter (1990, 1998), Schmitz (1992), UK Department (1999), Zaccarelli et al. (2008), Kamath, Agrawal e Chase (2012). Pereira et al. (2014) apresentam uma síntese da proposta de cada um destes estudos e constata que o modelo proposto por Zaccarelli et al. (2008) contempla o maior número de fatores utilizados para a análise da competitividade.

Em perspectivas diferentes, mas em muitos aspectos alinhadas entre si, os estudos que analisaram a competitividade de clusters discutem os fatores necessários ao alinhamento de desempenho competitivo de um cluster. Dentre estes aspectos, destaca-se a reincidência de questões relativas à concentração geográfica, as relações de cooperação e disseminação de conhecimento, a capacidade de inovação decorrente desta partilha, dentre outros benefícios da concentração, tais como presença de infraestrutura, mão-de-obra e fornecedores.

Embora a amplitude e complementaridade de um cluster sejam de fato importantes para sua dinâmica competitiva, outro aspecto tão ou mais importante para fundamentar essa análise é o estabelecimento de parâmetros que permitam auferir o nível de desempenho deste cluster (SHAFEI, 2009). Observa-se que os modelos existentes na literatura são de natureza descritiva e em alguns casos não endereçam métricas específicas para mensurar cada uma das dimensões abordadas (PEREIRA et al., 2014). Ao ajustar as métricas em consonância com a realidade de cada ambiente de estudo, a literatura ainda não avançou na consolidação de métricas que possam ser replicadas em diferentes tipos de clusters.

\section{Metodologia}

O objetivo deste estudo foi identificar, comparar e consolidar modelos empregados na análise da competitividade dos clusters a partir dos estudos nacionais no período de 2000 a 2016. Para tanto, empreendeu-se uma pesquisa qualitativa e bibliográfica a fim de analisar as características da produção científica sobre competitividade em clusters.

Para gerar um inventário dos modelos, fundamentos e suas métricas para avaliação da competitividade em aglomerados, utilizou-se o método de revisão sistemática da literatura. A revisão sistemática "difere das revisões narrativas tradicionais, pois adotam um processo replicável, científico e transparente, ou seja, tem uma metodologia detalhada" (TRANFIELD; DENYER; SMART, 2003, p. 209). "A revisão sistemática deve ser estruturada em passos detalhados e que permitam que os resultados respondam ao problema de pesquisa levantado" (CHUEKE; AMATUCCI, 2015, p.3). 
Figura 1 - Protocolo de Pesquisa
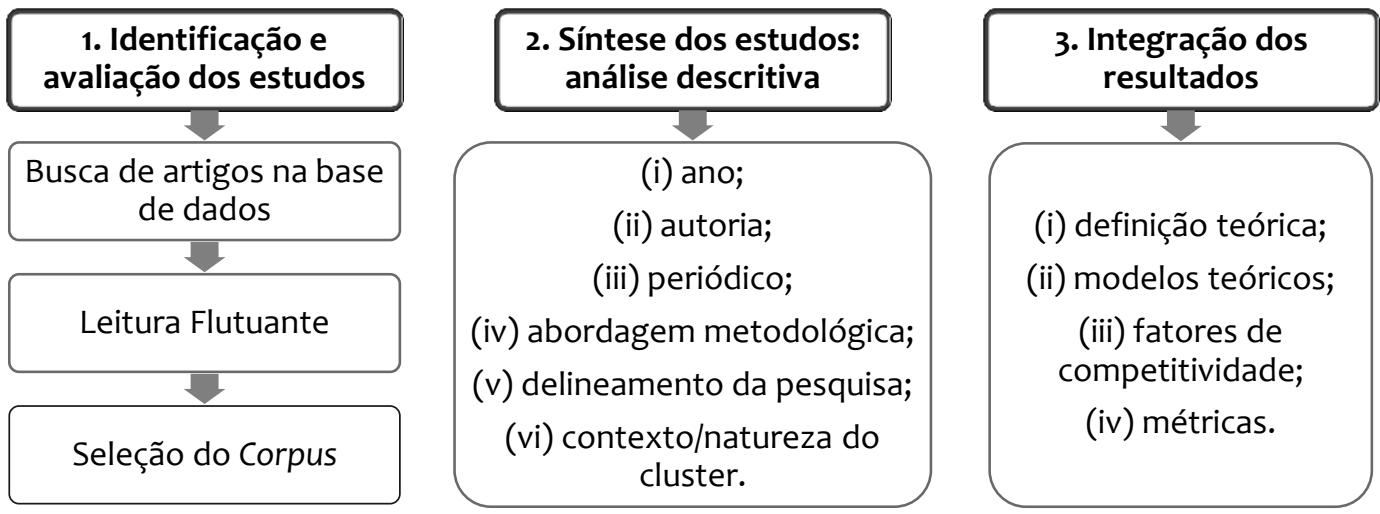

Fonte: Elaborada pelas autoras.

Conforme apresentado na Figura 1, os passos propostos pelos autores são: elaboração do protocolo de pesquisa, identificação dos estudos mais relevantes, avaliação da qualidade dos estudos selecionados, síntese dos dados coletados e integração dos resultados obtidos. Para operacionalização da pesquisa, esses passos foram desenvolvidos em três etapas.

Os artigos foram coletados na base de dados SPELL Scientific Periodicals Electronic Library, escolhida por constituir-se em um amplo e relevante repositório da produção científica nacional. Definida a base, para determinação da amostra, estabeleceram-se como critérios de busca os termos "cluster" e "arranjo produtivo local" no título dos artigos, combinados com os termos "vantagem competitiva", "competitividade" e "competição" nos campos resumo e palavras-chave.

Após a coleta dos artigos, os dados foram tabulados e organizados. $\mathrm{Na}$ análise descritiva os artigos foram classificados por:

(i) Ano de publicação do artigo.

(ii) Autores que publicaram os artigos.

(iii) Periódico em que o artigo foi publicado.

(iv) Abordagem metodológica utilizada, considerando as subcategorias propostas por Machado-da-Silva et al. (1989), quais sejam: empírica, teórico-empírica e teórica.

(v) Delineamento da pesquisa conforme a classificação de Gil (2008): estudo de caso, estudo de campo, survey e pesquisa documental

(vi) Contexto/natureza do cluster pesquisado em função de sua atividade econômica.

$\mathrm{Na}$ integração dos resultados, ou seja, análise que gerem os resultados que respondam ao problema de pesquisa levantado, os artigos foram categorizados em função de:

(i) Definição teórica utilizada: analisa a fundamentação utilizada na delimitação do modelo de análise de competitividade do cluster. $E$ também a definição característica do agrupamento (cluster, APL, aglomerado, sistema produtivo, dentre outras) adotada no estudo.

(ii) Modelos teóricos aplicados: verifica quais modelos foram utilizados pelos artigos na análise de competitividade do cluster.

(iii) Fatores de competitividade avaliados: verifica quais fatores/fundamentos foram empregados na proposta de análise de competitividade do cluster. 
(iv) Métricas consolidadas: proposta de consolidação das métricas que foram utilizadas para operacionalizar a avaliação dos fatores de competitividade no cluster.

\section{Análise dos resultados}

$\mathrm{Na}$ análise dos resultados, primeiro é apresentada uma análise descritiva dos estudos encontrados, fornecendo um panorama das publicações sobre o tema. Em seguida é apresentado um levantamento dos modelos, fatores e métricas empregadas para a avaliação da competitividade de clusters de negócios.

\subsection{Análise descritiva}

A pesquisa na base de dados SPELL, conforme os critérios mencionados, resultou na localização de 136 artigos. Posteriormente a eliminação dos achados em duplicidade, apurou-se um total de 77 artigos que compuseram a amostra inicial. Após uma leitura flutuante retirou-se 4 artigos onde o termo cluster referia-se a uma técnica estatística e não ao conceito de cluster de negócios. A amostra final foi composta por 73 artigos. A distribuição destes artigos no tempo é delineada no Gráfico 1.

\section{Gráfico 1 - Total de artigos por ano}

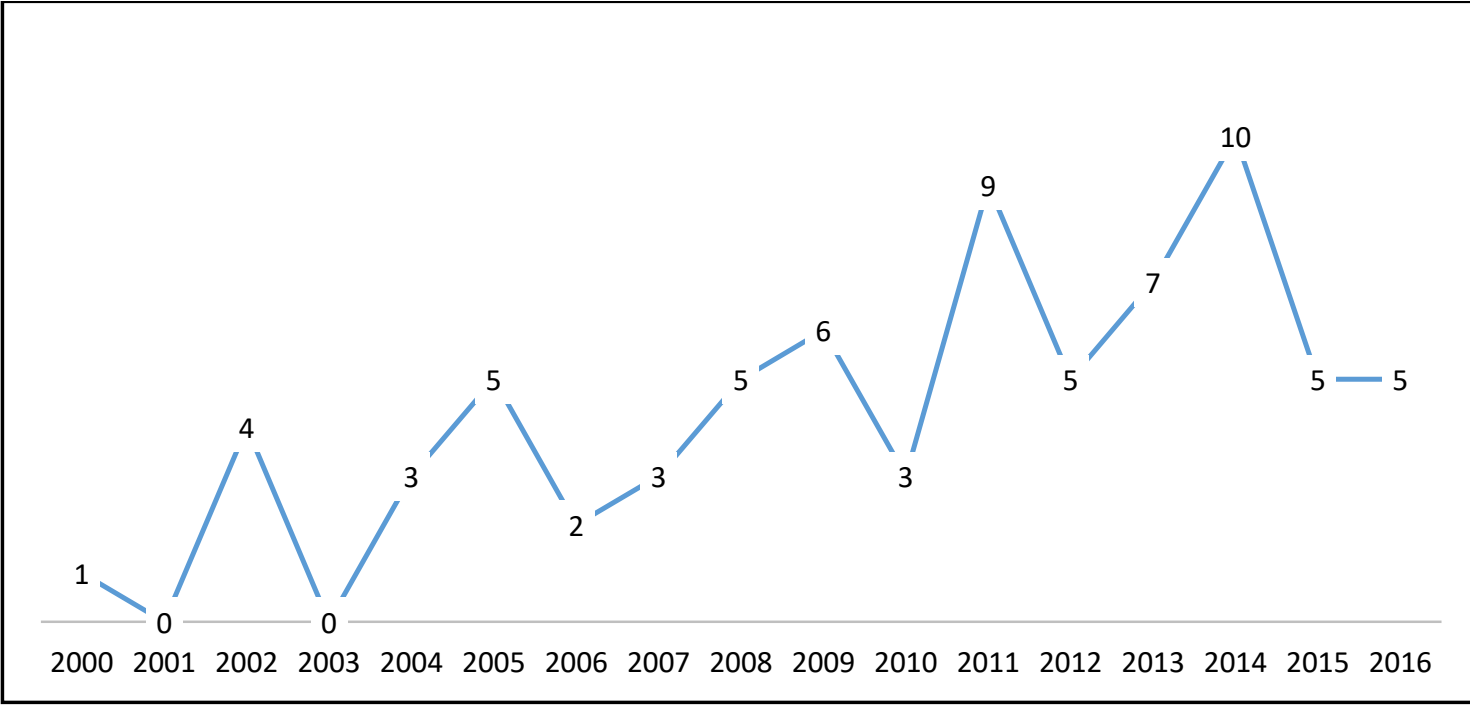

Fonte: Dados da pesquisa.

Realizada a análise, os 73 artigos foram classificados quanto à sua abordagem metodológica rotulando-se 57 artigos teórico-empíricos, 12 artigos teóricos e 4 artigos empíricos. Os artigos teórico-empíricos e empíricos (61 artigos ao todo) foram classificados conforme o delineamento da pesquisa observando-se a distribuição no Quadro 1. Também é possível observar no Quadro 1 a preponderância dos estudos de caso na amostra, correspondendo a $72 \%$ dos estudos empíricos levantados. 
Quadro 1- Delineamento da pesquisa

\begin{tabular}{|lc|}
\hline \multicolumn{1}{|c|}{ Delineamento de pesquisa } & $\mathbf{N}^{\circ}$ de publicações \\
\hline Estudo de Caso & 44 \\
Estudo de Campo & 7 \\
Survey & 8 \\
Pesquisa Documental & 2 \\
\hline Total de artigos empíricos & 61 \\
\hline
\end{tabular}

Fonte: Dados da pesquisa.

Em relação aos pesquisadores, destacam-se 7 autores que foram reincidentes em mais de um estudo, conforme Quadro 2. A maioria destes, provenientes da região sudeste, a exceção de um pesquisador com vínculo em uma instituição da região sul, e um da região centro-oeste. As regiões norte e nordestes não apresentaram representantes.

Quadro 1 - Autores reincidentes em publicações

\begin{tabular}{|llcc|}
\hline \multicolumn{1}{c}{ Autor } & \multicolumn{1}{c|}{ Filiação Institucional } & Estado & $\mathbf{N}^{\circ}$ de publicações \\
\hline João Maurício Gama Boaventura & FEA - USP & SP & 3 \\
Valmir Emil Hoffmann & UNB & DF & 3 \\
Cristiana Fernandes de Muylder & Universidade FUMEC & MG & 2 \\
Fábio Lotti Oliva & FEA - USP & SP & 2 \\
João Paulo Lara de Siqueira & Uninove & SP & 2 \\
Marcos Antonio Gaspar & Uninove & SP & 2 \\
Milton Luiz Wittmann & UFSM & RS & 2 \\
Pâmella Gabriela Oliveira Pugas & Centro Universitário UNA & MG & 2 \\
Renato Telles & UNIP & SP & 2 \\
\hline
\end{tabular}

Fonte: Dados da pesquisa.

Em relação à fonte das publicações, constatou-se um total de 42 periódicos distintos, dentre os quais foram destacados aqueles que apresentaram mais de duas publicações no período analisado, conforme estratificado no Quadro 3.

Quadro 3-Periódicos com mais publicações

\begin{tabular}{|lc|}
\hline \multicolumn{1}{|c|}{ Periódico } & No de publicações \\
\hline Revista IberoAmericana de Estratégia & 5 \\
Contextus Revista Contemporânea de Economia e Gestão & 4 \\
Revista da Micro e Pequena Empresa & 4 \\
Revista de Administração e Inovação & 4 \\
Revista de Ciências da Administração & 4 \\
Turismo: Visão e Ação & 4 \\
Desenvolvimento em Questão & 3 \\
Gestão \& Regionalidade & 3 \\
Revista de Administração & 3 \\
Revista de Administração Pública & 3 \\
Outros & 32 \\
\hline
\end{tabular}

Fonte: Dados da pesquisa 
Após a leitura de cada um dos 73 artigos, selecionaram-se aqueles que adotavam algum critério embasado na literatura para analisar a competitividade de clusters. Esta triagem visou eleger uma amostra que permitisse o levantamento dos fundamentos e métricas para analisar a competitividade de clusters, tendo como finalidade atingir o objetivo proposto neste artigo. O corpus selecionado para esta análise é constituído por 23 artigos teórico-empíricos, apresentados no Quadro 4.

Quadro 4 - Artigos avaliados na análise qualitativa

\begin{tabular}{|c|c|c|c|}
\hline & & $(\mathrm{c}$ & inua \\
\hline & Título & Autores & Ano \\
\hline 1 & $\begin{array}{c}\text { A competitividade, segundo a análise de um grande cluster de produção } \\
\text { agroindustrial }\end{array}$ & $\begin{array}{l}\text { SUGANO e } \\
\text { SANTOS }\end{array}$ & 2000 \\
\hline 2 & $\begin{array}{l}\text { Clusters em bioindústria e biotecnologia em Minas Gerais Habitats } \\
\text { construídos de inovação, competitividade e desenvolvimento regional }\end{array}$ & JUDICE e BAETA & 2002 \\
\hline 3 & Análise do cluster vinícola de São Roque & $\begin{array}{l}\text { CONTADOR, } \\
\text { CONTADOR e } \\
\text { OLIVEIRA }\end{array}$ & 2004 \\
\hline 4 & $\begin{array}{l}\text { Vantagens competitivas em clusters industriais: estudo de caso no setor } \\
\text { cerâmico paulista }\end{array}$ & $\begin{array}{l}\text { TOLEDO e } \\
\text { GOLDSTEIN }\end{array}$ & 2008 \\
\hline 5 & $\begin{array}{l}\text { A competitividade nos Clusters da indústria de borracha do sudeste } \\
\text { asiático }\end{array}$ & MAZZARO et al. & 2009 \\
\hline 6 & $\begin{array}{l}\text { O Arranjo Produtivo Local como potencializador da vantagem competitiva: } \\
\text { a visão dos participantes do APL de Turismo Região Lagoas em Alagoas }\end{array}$ & SGARBI & 2009 \\
\hline 7 & $\begin{array}{l}\text { Arranjo Produtivo Local: oportunidades e desafios para implementação da } \\
\text { cadeia produtiva da vitivinicultura na região de Jundiaí }\end{array}$ & CALHEIROS & 2010 \\
\hline 8 & $\begin{array}{c}\text { Recursos compartilhados como fonte competitiva em empresas } \\
\text { aglomeradas territorialmente: um estudo na indústria têxtil da Região de } \\
\text { Rio do Sul (SC) }\end{array}$ & $\begin{array}{l}\text { NECKEL, } \\
\text { HOFFMANN e } \\
\text { SCHOREDER }\end{array}$ & 2010 \\
\hline 9 & $\begin{array}{l}\text { Benefícios da aglomeração de firmas: evidências do arranjo produtivo de } \\
\text { semijoias de Limeira }\end{array}$ & THOMAZ et al. & 2011 \\
\hline 10 & $\begin{array}{c}\text { Minimizando as barreiras para a medição de desempenho em arranjos } \\
\text { produtivos locais: o caso de Sertãozinho }\end{array}$ & $\begin{array}{l}\text { LIMA, MARINHO e } \\
\text { CARPINETTI }\end{array}$ & 2011 \\
\hline 11 & $\begin{array}{l}\text { Clusters comerciais: um estudo sobre concentrações de bares na cidade de } \\
\text { São Paulo }\end{array}$ & TELLES et al. & 2011 \\
\hline 12 & $\begin{array}{l}\text { Análise da competitividade dos clusters industriais de calçados de Franca e } \\
\text { Birigui }\end{array}$ & $\begin{array}{l}\text { SIQUEIRA, GERTH } \\
\text { e BOAVENTURA }\end{array}$ & 2011 \\
\hline 13 & Análise da competitividade do APL de piscicultura no lago de Três Marias & $\begin{array}{l}\text { CASTRO, MAFUD, e } \\
\text { SCARE }\end{array}$ & 2011 \\
\hline 14 & $\begin{array}{l}\text { Competitividade sistêmica no Arranjo Produtivo Local de colchões em } \\
\text { Campina Grande PB }\end{array}$ & $\begin{array}{l}\text { SILVA, SANTOS e } \\
\text { CÂNDIDO }\end{array}$ & 2011 \\
\hline 15 & $\begin{array}{l}\text { Competitividade de clusters comerciais: estudo sobre uma aglomeração de } \\
\text { pequenas lojas de veículos no Município de São Paulo }\end{array}$ & DONAIRE et al. & 2013 \\
\hline 16 & $\begin{array}{l}\text { O Cluster cinematográfico de Paulínia: uma análise da inovação e do } \\
\text { empreendedorismo da indústria do cinema em Paulínia SP }\end{array}$ & UCHOA e DIAS & 2013 \\
\hline 17 & $\begin{array}{l}\text { Aglomerados e visão baseada em recursos: as capacidades organizacionais } \\
\text { de empresas inseridas em um aglomerado do setor de vestuário em Minas } \\
\text { Gerais }\end{array}$ & $\begin{array}{l}\text { PUGAS, } \\
\text { CALEGARIO e } \\
\text { ANTONIALLI }\end{array}$ & 2013 \\
\hline 18 & $\begin{array}{l}\text { Desenvolvimento de métricas para avaliação da competitividade de } \\
\text { Clusters: uma aplicação empírica no setor têxtil }\end{array}$ & PEREIRA et al. & 2014 \\
\hline
\end{tabular}


(conclusão)

\begin{tabular}{|c|c|c|c|}
\hline & Título & Autores & Ano \\
\hline 19 & $\begin{array}{l}\text { Fatores condicionantes da competitividade exportadora do cluster de rochas } \\
\text { ornamentais do Espírito Santo }\end{array}$ & $\begin{array}{l}\text { MACLENNAN et } \\
\text { al. }\end{array}$ & 2014 \\
\hline 20 & $\begin{array}{l}\text { Análise da competitividade do cluster de confecções no Município de } \\
\text { Campina Grande, PB }\end{array}$ & LACERDA et al. & 2015 \\
\hline 21 & $\begin{array}{l}\text { Análise de efetividade das políticas públicas de Arranjo Produtivo Local para } \\
\text { o desenvolvimento local a partir da teoria institucional }\end{array}$ & JACOMETTI et al. & 2016 \\
\hline 22 & $\begin{array}{c}\text { Competitividade das Empresas no Arranjo Produtivo Local de Grãos em } \\
\text { Santarém e Belterra/Pará }\end{array}$ & $\begin{array}{l}\text { OLIVEIRA e } \\
\text { SANTANA }\end{array}$ & 2016 \\
\hline 23 & $\begin{array}{c}\text { Um Instrumento de Pesquisa Qualitativo para Analisar Fatores de } \\
\text { Competitividade de Conglomerados Organizacionais }\end{array}$ & HOPPEN et al. & 2016 \\
\hline
\end{tabular}

Fonte: Elaborado pelas autoras.

Dentre os artigos, 21 realizam estudo de caso e apenas dois apresentam survey como delineamento de pesquisa (SIQUEIRA; GERTH; BOAVENTURA, 2011; CASTRO; MAFUD; SCARE, 2011). Estes artigos estão publicados em 18 revistas diferentes, com destaque para a Revista da Micro e Pequena Empresa que têm 3 artigos publicados e as revistas: Revista de Administração, Gestão \& Regionalidade, e, Organizações Rurais \& Agroindustriais, que têm 2 publicações cada uma. Todas as demais revistas apresentam apenas um artigo do corpus de artigos analisado.

Em relação ao contexto/natureza dos clusters pesquisados nestes artigos, encontram-se os mais diversos setores, aqui classificados em três grupos: agrícola, indústria e serviços. Em relação ao setor agrícola os estudos abordam: a cadeia agroindustrial do ovo; o setor vinícola; concentrações de pequenos agricultores, produtores de grão, produtores de flores e, piscicultura. No grupo do setor industrial encontram-se indústrias nos ramos de: bioindústria e biotecnologia; indústria têxtil; confecções; calçados; indústria metalomecânica; semi-jóias; colchões; cerâmica de revestimento; indústria cinematográfica; móveis; e, indústria da borracha. E, aqueles que estudam clusters de serviços, de natureza comercial incluem: turismo, têxteis e vestuário, bares, pequenas lojas de veículos, e, rochas ornamentais.

Apesar de estarem distribuídos por todo Brasil e até fora dele, nota-se predominância de estudos na região sudeste do país, sobretudo no Estado de São Paulo. Os setores por sua vez são totalmente distintos e heterogêneos, as terminologias cluster e APL são empregadas na mesma proporção para identificação das concentrações empresariais.

\subsection{Análise dos modelos e métricas de competitividade}

\subsubsection{Definição teórica de cluster}

Analisando-se a definição de cluster adotada nos estudos, verificou-se que a definição mais frequentemente empregada é a proposta por Porter (1990) e suas variações (PORTER, 1998; 1999), remetendo à ideia de "concentrações geográficas de companhias e instituições interconectadas em um campo particular". Além das menções à Porter (1990), outras referências internacionais utilizadas para determinação do conceito de agrupamento é a de Swann e Prevezer (1996), 
Baptista e Swann (1998), Maskell (2001), Morosini (2004) que se assemelham às proposições de Porter.

O emprego exclusivo do termo APL - arranjos produtivos locais foi verificado em três estudos que têm suas definições embasadas nas propostas das instituições Redesist (2003) e Ministério da Economia, Indústria, Comércio Exterior e Serviços Brasil (2018). Estas definições representam aglomerações territoriais de agentes econômicos, políticos e sociais, focados em atividades econômicas específicas, envolvendo empresas produtoras de bens e serviços, fornecedoras de insumos e equipamentos, prestadoras de consultorias e serviços, comerciantes e clientes etc.

Quatro estudos condensam o posicionamento de distintos pesquisadores (PORTER, 1989; 1990; AMATO NETO, 2000; CASSIOLATO, LASTRES e VARGAS; 2002; CASSIOLATO, 2003; LASTRES, CASSIOLATO e MACIEL, 2003; ZACCARELLI, 2003; SEBRAE, 2010) ampliando as definições para os diferentes tipos de aglomerados, incluindo sobretudo, clusters, arranjos produtivos locais e distritos industriais. Quatro dos estudos analisados, após realizarem alguma discussão conceitual sobre os aglomerados, apresentam definições autorais para descreverem os agrupamentos. A definição de cluster como entidade supra empresarial defendida por Zaccarelli et al. (2008) também foi utilizada.

\subsubsection{Modelos Teóricos}

Ao verificar os modelos teóricos empregados para embasar a análise de competitividade dos clusters, levantou-se na amostra pesquisada (apresentada no Quadro 4) o emprego de 14 modelos distintos, conforme o Quadro 5.

Quadro 5-Modelos teóricos de competitividade em clusters

\begin{tabular}{|l|c|c|}
\hline \multicolumn{1}{|c|}{ Modelo } & Fonte & Citações \\
\hline Análise da capacidade organizacional & $\begin{array}{c}\text { FERRAZ; KUPFER; } \\
\text { HAGUENAUER, 1995. }\end{array}$ & 1 \\
\hline Análise da capacidade organizacional & RANGONE, 1999. & 1 \\
\hline Condições para o cluster ser completo & ZACCARELL, 1995. & 1 \\
\hline $\begin{array}{l}\text { Fatores competitivos da empresa na perspectiva dos distritos } \\
\text { industriais }\end{array}$ & HOFFMANN, 2002. & 1 \\
\hline Fatores determinantes da competitividade em um cluster & $\begin{array}{l}\text { TOLEDO e SZAFIR- } \\
\text { GOLDSTEIN, 2008. }\end{array}$ & 1 \\
\hline Fatores determinantes da competitividade sistêmica & COUTINHO e FERRAZ, 1994. & 1 \\
\hline $\begin{array}{l}\text { Fatores que explicam o desempenho superior das empresas do } \\
\text { cluster - benefícios da aglomeração }\end{array}$ & THOMAZ et al., 2011. & 1 \\
\hline Framework para medir o desempenho de um APL & CARPINETTI; CARDOZA; & 1 \\
\hline Fundamentos da performance competitiva de clusters & ZACCARELLI et al., 2008. & 5 \\
\hline Modelo de análise das influências ambientais & ALMEIDA, 1997. & 1 \\
\hline Modelo de competitividade sistêmica & ESSER et al., 1994. & 1 \\
\hline Modelo Diamante & PORTER, 1990. & 3 \\
\hline Requisitos para um cluster completo & ZACCARELLI, 2000. & 2 \\
\hline Vantagem Competitiva & PORTER, 1986. & 1 \\
\hline $\begin{array}{l}\text { Análise da efetividade de políticas públicas na competitividade } \\
\text { de um APL }\end{array}$ & JACOMETI et al., 2016. & 1 \\
\hline Índice de Desempenho Competitivo (IDC) & SANTANA, 2007. & 1 \\
\hline Fatores de competitividade & HOPPEN et al., 2016. & 1 \\
\hline
\end{tabular}

Fonte: Elaborado pelas autoras. 
Dentre os modelos identificados, 3 foram utilizados por mais de um artigo: Zaccarelli (2000), Zaccarelli et al. (2008) e Porter (1990). Zaccarelli e Porter foram, portanto, os autores mais citados, o primeiro com 7 e o segundo com 4 citações, considerando-se todos os seus modelos. Ressalta-se que em apenas um artigo foi utilizado mais de um modelo (FERRAZ; KUPFER; HAGUENAUER, 1995; RANGONE, 1999).

Porter propôs o Modelo Diamante (1990), a princípio, não para analisar a competitividade dos clusters, mas sim a competitividade das nações (ou regiões). Porém, a operacionalização deste modelo em 3 dos estudos analisados demonstra sua aplicação à dimensão dos clusters. O modelo de análise da Vantagem Competitiva (1986) é anterior à concepção da terminologia cluster, mas, por suas características, embora não tenha se desenvolvido para este fim, também se mostrou aplicável a este tipo de análise.

Os trabalhos de Zaccarelli tem um caráter evolutivo; os estudos de 1995, 2000 e 2003 apresentam aspectos necessários para que um agrupamento empresarial seja considerado um cluster, esses aspectos são incorporados ao longo de sua produção e em 2008 com o auxílio de colaboradores, culminam na proposição dos fundamentos da performance competitiva dos clusters. Nos estudos empíricos pesquisados, este modelo mostra-se o mais aplicado.

Esser et al. (1994), Coutinho e Ferraz (1994) e Jacometi et al. (2016) apresentam modelos voltados para análise da competitividade sistêmica. Sua aplicação para verificação deste fenômeno em clusters é subsidiada pela proposição de que estes agrupamentos se constituem efetivamente em sistemas, conforme afirmam Zaccarelli et al. (2008). A aplicação do modelo de Almeida (1997) é um tanto quanto peculiar, uma vez que se trata de uma análise fundamentada em mapeamento estratégico e diagnóstico de ambiente, contudo, não deixa de ser aplicável se considerada a natureza estratégica dos clusters (ZACCARELLI et al., 2008).

Os modelos decorrentes das propostas de Ferraz, Kupfer e Haguenauer (1995), Rangone (1999), Hoffmann (2002) e Santana (2007) são voltados para análise da capacidade competitiva das empresas e não do cluster propriamente dito. O diferencial dos estudos empíricos que aplicaram estes modelos está em analisar como a inserção no cluster favorece o desenvolvimento destas capacidades nas organizações, diferentemente do modelo de Carpinetti, Cardoza e Gerolamo (2008), que propõe medir o desempenho do arranjo como um todo, na perspectiva de uma entidade supra empresarial. E, por fim, Toledo e Szafir-Goldstein (2008), Thomaz et al. (2011) e Hoppen et al. (2016) apresentam modelos autorais voltados para identificação de fatores que determinam e explicam a competitividade dos clusters em âmbito geral. No trabalho de Hoppen et al. (2016) os autores desenvolveram um modelo bastante complexo cujo instrumento de pesquisa abrange construtos, fatores e itens. É importante deixar claro que, para este trabalho, consideraram-se os construtos como correspondentes aos Fatores de Competitividade aqui investigados. 


\subsubsection{Fatores de Competitividade}

Os fatores de competitividade componentes dos modelos discutidos no tópico anterior foram compilados em função de sua similaridade e são apresentados no Quadro 6.

Quadro 6 - Fatores de competitividade dos modelos aplicados nos artigos

\begin{tabular}{|c|c|c|c|}
\hline & & & ontinua) \\
\hline ID & $\begin{array}{c}\text { Fatores de } \\
\text { competitividade } \\
\text { encontrados }\end{array}$ & Modelos que apresentam o fator & $\begin{array}{l}\mathrm{N}^{\circ} \text { art. que } \\
\text { utilizaram }\end{array}$ \\
\hline 1 & $\begin{array}{l}\text { Cooperação entre } \\
\text { empresas }\end{array}$ & $\begin{array}{c}\text { Esser et al. (1994); Zaccarelli (1995, 2000, 2003); Hoffmann (2002); } \\
\text { Carpinetti, Cardoza e Gerolamo (2008); Zaccarelli et al. (2008); } \\
\text { Toledo e Szafir-Goldstein (2008); Thomaz et al. (2011); Jacometi et } \\
\text { al. (2016); Hoppen et al. (2016) }\end{array}$ & 14 \\
\hline 2 & $\begin{array}{l}\text { Abrangência de negócios } \\
\text { viáveis e relevantes }\end{array}$ & $\begin{array}{l}\text { Porter (1990); Almeida (1997); Zaccarelli (1995, 2000, 2003); } \\
\text { Zaccarelli et al. (2008); Thomaz et al. (2011); Hoppen et al. (2016) }\end{array}$ & 13 \\
\hline 3 & $\begin{array}{l}\text { Inovação, conhecimento, } \\
\text { caráter evolucionário por } \\
\text { introdução de (novas) } \\
\text { tecnologias }\end{array}$ & $\begin{array}{c}\text { Porter (1986); Esser et al.(1994); Ferraz, Kupfer e Haguenauer } \\
\text { (1995); Rangone (1999); Hoffmann (2002); Zaccarelli et al. (2008); } \\
\text { Toledo e Szafir-Goldstein (2008); Thomaz et al. (2011); Santana } \\
\text { (2007); Hoppen et al. (2016) }\end{array}$ & 12 \\
\hline 4 & Nível tecnológico & $\begin{array}{l}\text { Porter (1986); Esser et al. (1994); Zaccarelli (1995, 2000, 2003); } \\
\text { Zaccarelli et al. (2008); Thomaz et al. (2011); Hoppen et al. (2016). }\end{array}$ & 11 \\
\hline 5 & $\begin{array}{l}\text { Estratégias coletivas } \\
\text { orientadas para } \\
\text { diminuição de riscos e } \\
\text { criação de vantagens } \\
\text { competitivas para o } \\
\text { cluster }\end{array}$ & $\begin{array}{c}\text { Porter (1990); Zaccarelli et al.(2008); Carpinetti, Cardoza e } \\
\text { Gerolamo (2008); Thomaz et al.(2011); Santana (2007); Hoppen et } \\
\text { al. (2016) }\end{array}$ & 11 \\
\hline 6 & $\begin{array}{l}\text { Fatores Políticos e } \\
\text { Econômicos }\end{array}$ & $\begin{array}{l}\text { Porter (1990); Esser et al. (1994); Coutinho e Ferraz (1994); Almeida } \\
\text { (1997); Carpinetti, Cardoza e Gerolamo (2008); Thomaz et al. (2011); } \\
\text { Santana (2007); Jacometi et al. (2016); Hoppen et al. (2016) }\end{array}$ & 11 \\
\hline 7 & $\begin{array}{l}\text { Equilíbrio de mercado } \\
\text { com ausência de } \\
\text { posições privilegiadas }\end{array}$ & $\begin{array}{c}\text { Porter (1990); Coutinho e Ferraz (1994); Zaccarelli et al. (2008); } \\
\text { Thomaz et al. (2011) }\end{array}$ & 9 \\
\hline 8 & $\begin{array}{l}\text { Cultura da comunidade } \\
\text { adaptada ao cluster }\end{array}$ & $\begin{array}{l}\text { Esser et al. (1994); Almeida (1997); Zaccarelli (2000, 2003); } \\
\text { Zaccarelli et al. (2008); Hoppen et al. (2016) }\end{array}$ & 9 \\
\hline 9 & $\begin{array}{l}\text { Intensa disputa: } \\
\text { substituição seletiva } \\
\text { permanente; regulação } \\
\text { da concorrência }\end{array}$ & $\begin{array}{c}\text { Coutinho e Ferraz (1994); Zaccarelli (1995, 2000, 2003); Zaccarelli et } \\
\text { al. (2008); Santana (2007) }\end{array}$ & 9 \\
\hline 10 & Concentração geográfica & $\begin{array}{c}\text { Zaccarelli (1995, 2000, 2003); Hoffmann (2002); Zaccarelli et al. } \\
\text { (2008); Hoppen et al. (2016) }\end{array}$ & 9 \\
\hline 11 & $\begin{array}{l}\text { Especialização das } \\
\text { empresas }\end{array}$ & $\begin{array}{c}\text { Zaccarelli (1995, 2000, 2003); Zaccarelli et al. (2008); Thomaz et al. } \\
\text { (2011); Hoppen et al. (2016) }\end{array}$ & 9 \\
\hline
\end{tabular}


(conclusão)

\begin{tabular}{|c|c|c|c|}
\hline ID & $\begin{array}{c}\text { Fatores de } \\
\text { competitividade } \\
\text { encontrados }\end{array}$ & Modelos que apresentam o fator & $\begin{array}{l}\mathrm{N}^{\circ} \text { art. que } \\
\text { utilizaram }\end{array}$ \\
\hline 12 & $\begin{array}{l}\text { Alta especialização das } \\
\text { empresas e da mão de } \\
\text { obra }\end{array}$ & $\begin{array}{c}\text { Ferraz, Kupfer e Haguenauer (1995); Rangone (1999); Almeida } \\
\text { (1997); Zaccarelli (1995, 2000, 2003); Hoffmann (2002); Thomaz et } \\
\text { al. (2011); Hoppen et al. (2016) }\end{array}$ & 8 \\
\hline 13 & $\begin{array}{l}\text { Condição dos fatores de } \\
\text { produção e desempenho }\end{array}$ & $\begin{array}{l}\text { Porter (1990); Coutinho e Ferraz (1994); Ferraz, Kupfer e } \\
\text { Haguenauer (1995); Rangone (1999); Carpinetti, Cardoza e } \\
\text { Gerolamo (2008); Thomaz et al. (2011); Hoppen et al. (2016) }\end{array}$ & 8 \\
\hline 14 & $\begin{array}{l}\text { Complementariedade } \\
\text { por utilização de } \\
\text { subprodutos } \\
\end{array}$ & Zaccarelli (1995, 2000, 2003); Zaccarelli et al. (2008) & 7 \\
\hline 15 & $\begin{array}{l}\text { Compartilhamento de } \\
\text { apoio institucional }\end{array}$ & $\begin{array}{l}\text { Porter (1986); Coutinho e Ferraz (1994); Hoffmann (2002); Thomaz } \\
\text { et al. (2011); Santana (2007); Hoppen et al. (2016) }\end{array}$ & 6 \\
\hline 16 & $\begin{array}{l}\text { Compartilhamento de } \\
\text { infraestrutura e } \\
\text { condições sociais }\end{array}$ & $\begin{array}{l}\text { Esser et al. (1994); Coutinho e Ferraz (1994); Thomaz et al. (2011); } \\
\text { Santana (2007); Hoppen et al. (2016) }\end{array}$ & 5 \\
\hline 17 & $\begin{array}{l}\text { Acumulação de } \\
\text { competências gerenciais }\end{array}$ & $\begin{array}{l}\text { Porter (1986); Zaccarelli (1995); Coutinho e Ferraz (1994); Ferraz, } \\
\text { Kupfer e Haguenauer (1995) e Rangone (1999) }\end{array}$ & 4 \\
\hline 18 & Internacionalização & Esser et al.(1994); Coutinho e Ferraz (1994) & 2 \\
\hline 19 & Reputação & Hoffmann (2002); Thomaz et al. (2011) & 2 \\
\hline 20 & $\begin{array}{l}\text { Recursos de } \\
\text { financiamento/ } \\
\text { investimento }\end{array}$ & Porter (1986) & 1 \\
\hline
\end{tabular}

Fonte: Elaborado pelas autoras.

Dentre os fatores, os mais incidentes referem-se à cooperação entre as empresas (1) e a abrangência de negócios viáveis e relevantes (2). A cooperação constitui-se em uma espécie de catalisador, muito necessário para troca de recursos físicos e informacionais entre as empresas do cluster. Por sua vez, a abrangência de negócios influencia a competitividade através do acesso facilitado e custos mais acessíveis à fornecedores e insumos.

Considerando a interação existente entre os agentes de um cluster, observase nos fatores 3 e 4 que a partilha de informações e conhecimento suporta a difusão e o acesso mais rápido a inovações, promovendo uniformidade do nível tecnológico e a aquisição e desenvolvimento de novas tecnologias facilitado pelas externalidades positivas do cluster.

O estabelecimento de uma orientação coletiva (5), voltada para o alcance de vantagens competitivas para o cluster assegura que todos ali presentes se beneficiam de alguma forma, facilitando as relações dentro do arranjo, com equilíbrio de relações competitivas e cooperativas sem privilégios de uns em detrimento de outros, conforme o fator 7 .

A concentração geográfica (10), requisito inicial para determinação de um cluster também é considerada um fator de competitividade ao se pensar que quanto maior a concentração de empresas no cluster maior o seu potencial para acessar recursos partilhados pelas organizações componentes. Ressalta-se que conforme o fator 11, estas organizações, pela natureza aplicada de suas atividades, desenvolvem altos níveis de especialização que implicam em menores custos de 
desenvolvimento e produção. Este aspecto se relaciona à presença de mão-de-obra especializada (12) e acumulação de competências gerenciais e liderança (17).

A cultura da comunidade (8) se adapta às características do cluster presente na região, e, assim como a reputação (19), também passa a contribuir para o aumento da competitividade das empresas do cluster. Os fatores 18 e 20, internacionalização e financiamentos, surgem, em alguns casos, como consequência dos fatores 8 e 19.

A presença de concorrentes internos é um fator de competitividade por exigir que as empresas lutem para manter elevados padrões, resultando, em alguns casos, na uniformidade do desempenho, aspecto explicitado no $9^{\circ}$ fator de competitividade listado. Fatores políticos e econômicos (6) favoráveis, assim como o compartilhamento de apoio institucional (15), condições de produção (13) infraestrutura e condições sociais (16) e utilização de subprodutos (14) também influenciam a competitividade das empresas inseridas nos clusters e demonstram em uma análise global que pela natureza sistêmica de um cluster, a interação desses fatores em maior ou menor escala, asseguram a competitividade das empresas inseridas no mesmo, perante aquelas que atuam isoladas.

\subsubsection{Métricas Consolidadas}

Considerados os fatores de competitividade encontrados, realizou-se um levantamento das métricas empregadas para operacionalização de cada fator. Assim como os modelos, as métricas diferem de artigo para artigo, contudo, apresentam certo alinhamento quanto aos seus fins, permitindo a consolidação de um parâmetro unificado para cada fator de competitividade. A título de contribuição deste estudo, apresenta-se no Quadro 7 o resultado da consolidação e a respectiva proposição de métricas para verificação da competitividade em clusters. Alguns fatores utilizam métricas idênticas para obtenção de dados, porém, o tratamento e análise desses dados geram diferentes informações sobre sua competitividade.

Quadro 7-Métricas consolidadas

(continua)

\begin{tabular}{|c|c|c|c|}
\hline ID & Fatores de Competitividade & Métrica & Parâmetro \\
\hline $\begin{array}{c}2 \\
10\end{array}$ & $\begin{array}{l}\text { Abrangência } \\
\text { Concentração geográfica }\end{array}$ & $\begin{array}{l}N^{\circ} \text { de empresas correlatas instaladas no } \\
\text { cluster, categorizadas pelo CNAE }\end{array}$ & $\begin{array}{l}\text { Quanto maior, } \\
\text { melhor }\end{array}$ \\
\hline $\begin{array}{c}1 \\
15\end{array}$ & $\begin{array}{l}\text { Cooperação } \\
\text { Apoio institucional } \\
\text { Infraestrutura e condições } \\
\text { sociais }\end{array}$ & $\begin{array}{l}\mathrm{N}^{\circ} \text { médio de parcerias estabelecidas entre } \\
\text { as empresas e formação de associações } \\
\text { para compartilhamento de informações e } \\
\text { recursos - determinado por amostra de } \\
\text { executivos do cluster }\end{array}$ & $\begin{array}{l}\text { Quanto maior, } \\
\text { melhor }\end{array}$ \\
\hline
\end{tabular}


(conclusão)

\begin{tabular}{|c|c|c|c|}
\hline ID & Fatores de Competitividade & Métrica & Parâmetro \\
\hline 11 & Especialização das empresas & $\begin{array}{l}\text { \% de etapas da cadeia produtiva que são } \\
\text { realizadas pelas empresas do cluster }\end{array}$ & $\begin{array}{l}\text { Quanto maior, } \\
\text { melhor }\end{array}$ \\
\hline 4 & $\begin{array}{l}\text { Inovação e caráter } \\
\text { evolucionário } \\
\text { Nível tecnológico }\end{array}$ & $\begin{array}{l}\text { Presença de infraestrutura e associações } \\
\text { para pesquisa e desenvolvimento e } \\
\text { compartilhamento de informações } \\
\text { voltadas à inovação e acesso à tecnologia. }\end{array}$ & $\begin{array}{c}\text { Quanto mais } \\
\text { desenvolvida, melhor }\end{array}$ \\
\hline 7 & Equilíbrio de mercado & $\begin{array}{l}\text { Número total de empresas por atividade } \\
\text { desenvolvida no setor de atuação do } \\
\text { cluster }\end{array}$ & $\begin{array}{l}\text { Quanto mais } \\
\text { empresas atuem na } \\
\text { mesma atividade, } \\
\text { maior será o } \\
\text { equilíbrio }\end{array}$ \\
\hline 9 & Intensa disputa & $\begin{array}{l}\text { Índices estatísticos de encerramento de } \\
\text { empresas e de abertura de novas } \\
\text { empresas (\%). }\end{array}$ & $\begin{array}{c}\text { Número de } \\
\text { encerramentos deve } \\
\text { ser menor que o de } \\
\text { aberturas }\end{array}$ \\
\hline 5 & Estratégias coletivas & $\begin{array}{l}\text { Presença de: a) associações e instituições } \\
\text { de apoio; e b) realização de eventos } \\
\text { coletivos, e ações de melhoria coletiva, } \\
\text { como infraestrutura e aspectos } \\
\text { urbanísticos }\end{array}$ & Quanto mais, melhor \\
\hline 12 & $\begin{array}{l}\text { Cultura } \\
\text { Especialização da mão de } \\
\text { obra }\end{array}$ & $\begin{array}{l}\mathrm{N}^{\circ} \text { de trabalhadores relacionados ao } \\
\text { cluster dividido pela população da cidade }\end{array}$ & $\begin{array}{l}\text { Quanto maior, } \\
\text { melhor }\end{array}$ \\
\hline 13 & $\begin{array}{l}\text { Fatores de produção e } \\
\text { desempenho }\end{array}$ & $\begin{array}{l}\text { Índice de desempenho e capacitação, } \\
\text { estrutura patrimonial e produtiva e } \\
\text { articulações na cadeia - determinado por } \\
\text { amostra de executivos do cluster }\end{array}$ & $\begin{array}{c}\text { Quanto mais } \\
\text { desenvolvido, melhor }\end{array}$ \\
\hline 16 & Competências gerenciais & $\begin{array}{l}\text { Presença de princípios e técnicas de } \\
\text { gestão }\end{array}$ & $\begin{array}{l}\text { Quanto mais } \\
\text { desenvolvida, } \\
\text { melhor }\end{array}$ \\
\hline 14 & Utilização de subprodutos & $\begin{array}{l}\text { \% de aproveitamento de subprodutos e } \\
\text { reciclagem de materiais }\end{array}$ & $\begin{array}{l}\text { Quanto maior, } \\
\text { melhor }\end{array}$ \\
\hline 18 & Internacionalização & $\begin{array}{l}\text { Tendência do comércio, fluxo de capital e } \\
\text { acordos para o mercado externo - } \\
\text { determinado por amostra de executivos } \\
\text { do cluster }\end{array}$ & $\begin{array}{l}\text { Quanto mais } \\
\text { desenvolvidos, } \\
\text { melhor }\end{array}$ \\
\hline 19 & Reputação & $\begin{array}{l}\text { Percepção dos atores internos e externos } \\
\text { em relação ao cluster - determinado por } \\
\text { amostra de executivos do cluster e atores } \\
\text { externos }\end{array}$ & $\begin{array}{l}\text { Quanto mais positiva, } \\
\text { melhor }\end{array}$ \\
\hline 20 & Recursos de financiamento & $\begin{array}{l}\text { Nível de acesso a recursos financeiros } \\
\text { para desenvolvimento de atividades dos } \\
\text { negócios - determinado por amostra de } \\
\text { executivos do cluster }\end{array}$ & $\begin{array}{l}\text { Quanto maior, } \\
\text { melhor }\end{array}$ \\
\hline 6 & $\begin{array}{l}\text { Fatores Políticos e } \\
\text { Econômicos }\end{array}$ & $\begin{array}{l}\text { Avaliação qualitativa de fatores } \\
\text { relacionados a política econômica do país } \\
\text { e da região específica. }\end{array}$ & $\begin{array}{l}\text { Quanto maiores os } \\
\text { incentivos, melhor }\end{array}$ \\
\hline
\end{tabular}

Fonte: Elaborado pelas autoras. 
Conforme mencionado na introdução deste estudo, tão importante quanto identificar os fatores de competitividade de um cluster, é o estabelecimento de métricas para mensuração desses fatores. Dessa forma, trabalhar com fatores consolidados viabiliza a operacionalização da análise e comparação do desempenho competitivo dos clusters.

\section{Considerações finais}

O objetivo deste estudo foi identificar comparar e consolidar modelos empregados na análise da competitividade dos clusters a partir de estudos nacionais. A partir das análises, constatou-se crescente número de publicações sobre competitividade de clusters de negócios em estudos publicados no Brasil, apesar de relativa flutuação. As publicações nacionais sobre o tema são em sua maior parte teórico-empíricos e utilizam a abordagem de estudo de caso aplicando modelos já existentes.

Em relação à abordagem teórica empregada pelos artigos, a definição mais frequentemente empregada é a proposta por Porter (1990) e suas variações, remetendo à ideia de "concentrações geográficas de companhias e instituições interconectadas em um campo particular". Além de cluster, alguns trabalhos abordam as aglomerações como APLs, embasando-se nas propostas das instituições Redesist (2003) e Ministério da Economia, Indústria, Comércio Exterior e Serviços - Brasil (2018). Há também os estudos que condensam posicionamentos distintos e aqueles que apresentam definições autorais.

Nos 23 artigos analisados qualitativamente, identificaram-se 17 modelos utilizados para avaliar competitividade em clusters de negócios. Constatou-se que os modelos que contemplam maior número de fatores são Hoppen et al. (2016) com 12 fatores, e Zaccarelli et al. (2008) e Thomaz et al. (2011) com 11 fatores. Os modelos de Porter (1986; 1990) e Zaccarelli (1995; 2000; 2003; ZACCARELLI et al., 2008) são os mais utilizados, sendo o segundo o mais aplicado, indicando a influência deste autor em pesquisas nacionais sobre a competitividade em clusters.

Uma das principais contribuições deste estudo é a identificação dos fatores de competitividade, também chamados de fundamentos (ZACCARELLI, 1995; 2000; 2003; ZACCARELLI et al., 2008) ou construtos (HOPPEN et al., 2016), presentes nos modelos para a avaliação de clusters de negócios utilizados por autores brasileiros. Identificaram-se nos artigos que compuseram o corpus da pesquisa um total de 20 fatores, dentre eles os de maior incidência foram a Cooperação e a Abrangência de negócios viáveis e relevantes, citados em 13 e 12 dentre os 17 modelos analisados. Por outro lado, os fatores menos citados foram: Internacionalização, Reputação e Recursos de financiamento/investimento, indicando que há espaço para pesquisas sobre estes pontos, o que pode ser tomado como sugestão para pesquisas futuras.

Com relação às métricas empregadas na aplicação dos modelos pelos artigos analisados, contatou-se que não há uniformidade. Cada autor empregou métricas adaptadas ao seu objeto de pesquisa, no entanto, apesar de não haver uniformidade, estas métricas apresentam certo alinhamento, tornando possível consolidar uma métrica por fator. Em alguns fatores, a métrica escolhida para a consolidação é igual à métrica proposta em um dos modelos, em outros casos, 
optou-se por criar uma métrica adaptada para melhor refletir a riqueza dos modelos.

A principal contribuição desta pesquisa é fornecer uma consolidação dos fatores de competitividade de clusters e das métricas para avaliar esses fatores em estudos publicados no Brasil, portanto é predominantemente metodológica fundamentada no fornecimento de parâmetros consolidados para análise da competitividade de clusters de negócio. Além, disso, contribui ao oferecer um panorama da publicação nacional sobre competitividade em clusters. Este estudo, portanto, pode oferecer subsídios para futuros estudos empíricos que desejem avaliar a competitividade de clusters além de fornecer aos pesquisadores nacionais uma indicação das principais referências que orientam as publicações.

Ao focalizar estudos nacionais, este estudo se limitou a analisar artigos publicados no Brasil. Esta opção fez com que o levantamento de modelos, fatores e métricas representem $o$ panorama das publicações nacionais e não necessariamente a literatura internacional sobre o tema. Recomenda-se, que estudos futuros apliquem a metodologia desenvolvida nesta pesquisa em uma esfera internacional a fim de permitir a comparação dos resultados obtidos a partir da análise de estudos brasileiros com estudos internacionais.

\section{REFERÊNCIAS}

ALCÁCER, J.; CHUNG, W. Location Strategies for agglomeration economies. Harvard Business School Strategy Unit Working Paper, n. 10-071, p. 06-144, 2010.

ALMEIDA, M. I. R. Por que não desenvolver uma análise ambiental para o planejamento estratégico que tenha lógica e não seja apenas um agrupamento de informações? In: ENCONTRO DA ASSOCIAÇÃO NACIONAL DOS PROGRAMAS DE PÓS-GRADUAÇÃO EM ADMINISTRAÇÃO, 21, 1997, Rio das Pedras. Anais... Rio das Pedras: ENANPAD, 1997.1 CD-ROM.

AMATO NETO, J. Redes de cooperação produtiva e clusters regionais: oportunidades para as pequenas e médias empresas. Editora Atlas, 2000.

BAPTISTA, R; SWANN, P. Do firms in clusters innovate more? Research policy, v. 27, n. 5, p. 525-540, 1998.

BRASIL, MINISTÉRIO DO DESENVOLVIMENTO, INDÚSTRIA E COMÉRCIO EXTERIOR MDIC. Arranjos produtivos locais. 2018. Disponível em $<$ http://www.mdic.gov.br/index.php/competitividade-industrial/arranjos-produtivoslocais>

CARPINETTI, L.; CARDOZA, E.; GEROLAMO, M. A measurement system for managing performance of industrial clusters: a conceptual model and research cases.

International Journal of Productivity and Performance Management, v. 57, n. 5, p. 405-419, 2008. 
CHUEKE, G. V.; AMATUCCI, M. O que é bibliometria? uma introdução ao fórum. Internext, v. 10, n. 2, p. 1-5, 2015.

CASSIOLATO, J.; LASTRES, H.; VARGAS, M. Cooperação e competitividade de MPME: uma proposta de instrumentos financeiros voltados a arranjos produtivos locais. Artigo apresentado no V Fórum da Microempresa. Rio de Janeiro, p. 9-11, 2002.

COUTINHO, L.; FERRAZ, J. C. Estudos da competitividade da indústria brasileira. São Paulo: Papirus, 1994.

DE MARCHI, V.; GRANDINETTI, R. Industrial districts and the collapse of the Marshallian model: looking at the Italian experience. Competition \& Change, v. 18, n. 1, p. 70-87, 2014.

DI SERIO, L. C. Clusters Empresariais no Brasil: casos selecionados. São Paulo: Saraiva, 2007.

ESSER, K.; HILLEBRAND, W.; MESSNER, D.; MEYER-STAMER, J. Competitividad sistémica: competitividad internacional de las empresas y políticas requeridas. Instituto Alemán de Desarrollo, Berlin, 1994.

FERRAZ, J. C.; KUPFER, D. S.; HAGUENAUER, L. Made in Brazil: desafios competitivos para a indústria. Rio de Janeiro: Campus, 1995.

HOPPEN, N. et al. A qualitative research instrument to analyze organizational clusters' competitiveness factors. BASE-Revista de Administração e Contabilidade da Unisinos, v. 13, n. 1, p. 2-18, 2016.

GIL, A. C. Métodos e técnicas de pesquisa social. 6. ed. São Paulo: Atlas, 2008.

HE, J.; FALLAH, M. H. The typology of technology clusters and its evolutionEvidence from the hi-tech industries. Technological Forecasting and Social Change, v. 78, n. 6, p. 945-952, 2011.

HOFFMANN, V. E. Los Factores competitivos de la empresa a partir de la perspectiva de losdistritos industriales. Un estudio de la industria cerámica de revestimento brasileña. Tesis Doctoral Universidad de Zaragoza España, España: 2002.

HOOVER E.M. The Location of Economic Activity ( $1^{\text {st }}$ edn). McGraw-Hill Book Co.: New York, 1948.

JACOMETTI, M.; CASTRO, M. D.; GONÇALVES, S. A.; COSTA, M. C. Análise de efetividade das políticas públicas de Arranjo Produtivo Local para o desenvolvimento local a partir da teoria institucional. Revista de Administração Pública, v. 50, n. 3, p. 425-454, 2016. 
JACOSKI, C.; DALLACORTE, C.; BARICHELLO, R.; DEIMLING, M. F. Competitividade empresarial em clusters: uma análise bibliométrica da produção internacional. Iberoamerican Journal of Industrial Engineering, v. 6, n. 11, p. 74-93, 2014.

JUSTEN, G. S.; PAES-DE-SOUZA, M. Relações Sociais e Território: estudo no Arranjo Produtivo Local (APL) da castanha-da-Amazônia. Revista de Ciências da Administração, v. 19, n. 47, p. 114-130, 2017.

KAMATH, S; AGRAWAL, J; CHASE, K. Explaining geographic cluster Success - The GEMS model. American Journal of Economics and Sociology, v. 71, n. 1, p. 184-214, 2012.

KRUGMAN P.R. Geography and Trade Leuven, Belgium, Cambridge, MA. Published Jointly by Leuven University Press and MIT Press, 1991.

LACERDA, C. C. de O.; SOUZA, S. M. A. de; SILVA, A. L. L. da; SOUTO, W. B., Carlos César et al. Análise da competitividade do cluster de confecções no município de Campina Grande-PB. REUNIR: Revista de Administração, Contabilidade e Sustentabilidade, v. 5, n. 2, p. 1-24, 2015.

LASTRES, H. M.; CASSIOLATO, J. E. Glossário de arranjos e sistemas produtivos e inovativos locais. Rio de Janeiro: IE, 2003.

LASTRES, H. M. M.; CASSIOLATO, J. E.; MACIEL, M. L. Pequena empresa: cooperação e desenvolvimento local. Rio de Janeiro: Relume Damará, 2003.

LASTRES, H. M. M.; CASSIOLATO, J. E. Sistemas de inovação e desenvolvimento as implicações de política. São Paulo em Perspectiva, v.19, n 1, p. 34-45, jan/mar, 2005.

MACHADO-DA-SILVA, C; AMBONI, N; CUNHA, V. C. Produção acadêmica em administração pública: período 1983-88. In: ENCONTRO ANUAL DA ANPAD, 13, 1989, Águas de São Pedro. Anais... Águas de São Pedro: ANPAD, 1989.

MARINI, Marcos Junior; CORRÊA NETO, Gilcindo de Castro. Cooperação territorial: análise do capital social e da governança local do APL de Móveis do Sudoeste do Paraná. Redes (St. Cruz Sul, Online), Santa Cruz do Sul, v. 23, n. 3, p. 117-139, set. 2018. ISSN 1982-6745. Disponível em: https://online.unisc.br/seer/index.php/redes/article/view/12225 Acesso em: 22 mar. 2020. doi: https://doi.org/10.17058/redes.v23i3.12225

MARSHALL, A. Principles of Economics Book Four: The Agents of Production: Land, Labour, and Capital and Organization [Electronic version], 1890. Disponível em: https://www.marxists.org Acesso em: 14 de mai. 2015 
MASKELL, P. Towards a knowledge-based theory of the geographical cluster. Industrial and Corporate Change, 10(4), 2001, p. 921-943.

MOROSINI, P. Industrial clusters, knowledge integration and performance. World Development, 32(2), 2004, p. 305-326.

MOULAERT, F.; DJELLAL, F. Information technology consultancy firms: economies of agglomeration from a wide-area perspective. Urban Studies, v. 32, n. 1, p. 105-122, 1995.

NEWLANDS, D. Competition and cooperation in industrial clusters: the implications for public policy. European Planning Studies, 11(5), 2003, p.521-532.

OLIVEIRA, C. M. de; SANTANA, A. C. de. Competitividade das Empresas no Arranjo Produtivo Local de Grãos em Santarém e Belterra-Pará. Desenvolvimento em Questão, v. 14, n. 34, p. 351-382, 2016.

PEREIRA, C. E. C.; MASCENA, K. M. C.; PILLI, L. E.; MAZZON, J. A. Análise das publicações internacionais sobre vantagem competitiva em clusters: uma pesquisa bibliométrica. XVI SemeAd, São Paulo, outubro, 2013.

PEREIRA, C. E. C.; SARTURI, G.; BOAVENTURA, J. M. G.; POLO, E. F. Desenvolvimento de Métricas para Avaliação da Competitividade de Clusters: uma aplicação empírica no setor têxtil. Gestão \& Regionalidade, v. 30, n. 90, 2014.

PORTER, M. E. Estratégia Competitiva. Técnicas para Análise de Indústrias e da Concorrência. Rio de Janeiro, Editora Campus: 1986.

PORTER, M. E. From competitive advantage to corporate strategy. In: Readings in Strategic Management. Macmillan Education UK, 1989. p. 234-255.

PORTER, M. E. The competitive advantage of nations. New York: The Free Press, 1990.

PORTER, M. E. Clusters and the new economics of competition. Boston: Harvard Business Review, 1998.

PORTER, M. E. Competição. Rio de Janeiro. Campus, 1999.

RANGONE, A. A. Resource-based approach to strategy analysis in small-medium sized enterprises. Small Business Economics, Dordrecht, v.12, n.3, p.233-248, May 1999.

REDESIST Rede de Pesquisa. Produtivos e Inovativos Locais. Relatório de atividades do referencial conceitual,metodológico, analítico e propositivo - RedeSist. Rio de Janeiro: UFRJ/Sebrae, 2003. 
SACOMANO NETO, M.; PAULILLO, L. F. O. Estruturas de governança em arranjos produtivos locais: um estudo comparativo nos arranjos calçadistas e sucroalcooleiro no estado de São Paulo. Revista de Administração Pública - RAP, v. 46, n. 4, p. 11311155, 2012.

SANTANA, A. C. Análise do desempenho competitivo das agroindústrias de polpa de frutas do Estado do Pará. Teoria e Evidência Econômica, Passo Fundo, n. 14, p. 3662, jul/ dez. 2007.

SCHMITZ, H. On the clustering of small firms. IDS Bulletin, v.23, n.3, p. 64-69, 1992.

SCHMITZ, H. Eficiência coletiva: caminho de crescimento para a indústria de pequeno porte. Ensaios FEE, Porto Alegre, v.18, n.2, p.164-200, 1997

SEBRAE Serviço Brasileiro de Apoio às Micro e Pequenas Empresas. Arranjo Produtivo Local. Brasília: SEBRAE, 2010.

SHAFAEI, R. An analytical approach to assessing the competitiveness in the textile industry. Journal of Fashion Marketing and Management: An International Journal, v. 13, n. 1, p. 20-36, 2009.

SIQUEIRA, J. P.; GERTH, F. M.; BOAVENTURA, J. M. G. Análise da competitividade dos clusters industriais de calçados de Franca e Birigui. Revista Gestão Organizacional, v. 4, n. 2, p. 102-112, 2011.

SKOKAN, K.; ZOTYKOVÁ, L. Evaluation of Business Cluster Performance During Its Lifecycle. Acta Universitatis Agriculturae et Silviculturae Mendelianae Brunensis, v. 62, n. 6, p. 1395-1405, 2014.

SWANN, P.; PREVEZER, M. A comparison of the dynamics of industrial clustering in computing and biotechnology. Research Policy, v. 25, n. 7, p. 1139-1157, 1996.

TELLES, R. ALTHEMAN, E.; SIQUEIRA, J. P. L.; ROMBOLI, S. M. Clusters comerciais: um estudo sobre concentrações de bares na cidade de São Paulo. Gestão \& Regionalidade, v. 27, n. 81, 2012.

THOMAZ, J. C; BRITO, E. P. Z; MARCONDES, R. C; FERREIRA, F. C. M. Benefícios da aglomeração de firmas: evidências do arranjo produtivo de semijoias de Limeira.

RAUSP-Revista de Administração, v. 46, n. 2, p. 191-206, 2011.

TISCOSKI, G. P.; MORAES, R. C. A produção científica nacional sobre competitividade e cluster: A construção do campo de estudo no Brasil. XVI SEMEAD, São Paulo, outubro, 2013.

TOLEDO, G. L.; SZAFIR-GOLDSTEIN, C. Vantagens competitivas em clusters industriais: estudo de caso no setor cerâmico paulista. Revista de Economia e Administração, v. 7, n. 2, 2008. 
TRANFIELD, D.; DENYER, D.; SMART, P. Towards a methodology for developing evidence-informed management knowledge by means of systematic review. British Journal of Management, v.14, n. 3, p. 207-222, 2003.

UK Department of Trade and Industry. Biotechnology Clusters: report of a Team Led by Lord Sainsbury, Minister for Science, 1999.

WANG, L.; MADHOK, A.; XIAO LI, S. Agglomeration and clustering over the industry life cycle: Toward a dynamic model of geographic concentration. Strategic Management Journal, v. 35, n. 7, p. 995-1012, 2014.

ZACCARELLI, S. B. A nova ideologia da competição. Revista de Administração de Empresas, São Paulo, v.35, n.1, p.14-21. jan./fev, 1995.

ZACCARELLI, S. B. Clusters e redes de negócios: uma nova visão para a gestão dos negócios. São Paulo: Editora Atlas S.A, 2000.

ZACCARELLI, S. B. Estratégia e sucesso nas empresas. São Paulo: Saraiva, 2003.

ZACCARELLI, S. B.; TELLES, R.; SIQUEIRA, J. D.; BOAVENTURA, J. M. G.; DONAIRE, D. Clusters e redes de negócios: uma nova visão para a gestão dos negócios. São Paulo: Atlas, 2008.

Ana Cláudia Azevedo. Doutora em Administração pela FEA-USP. Filiação institucional: Universidade Federal de Viçosa, Centro de Ciências Humanas, Letras e Artes - CCH, Departamento de Administração e Contabilidade - DAD. Cargo: Professora Adjunta I. Endereço para correspondência: Av. Peter Henry Rolfs s/n - Campus Universitário, CEP: 36570000 - Viçosa/MG, Brasil. E-mail: anaazevedo@ufv.br

Cristina Espinheira Costa Pereira. Doutora em Administração pela FEAUSP. Filiação institucional: Centro Universitário FAM e Universidade Ibirapuera. Cargo: Professora do Programa de Pós-graduação e Graduação em Administração. Endereço para correspondência: R. Bela Cintra, 847 14 ${ }^{\circ}$ andar, Consolação, CEP: 01.415-910 - São Paulo/SP. E-mail: cristinaespinheira@gmail.com

Keysa Manuela Cunha de Mascena. Doutora em Administração pela FEAUSP. Filiação institucional. Professora do Programa de Pós-Graduação em Administração da Universidade de Fortaleza (PPGA/UNIFOR) e do Centro de Ciências da Comunicação e Gestão (CCG/UNIFOR). Endereço para correspondência: Av. Washington Soares, 1321 - Sala E01 - CEP 60.811-905 Fortaleza/CE. E-mail: keysamascena@unifor.br 
Como citar: AZEVEDO, Ana Cláudia; PEREIRA, Cristina Espinheira Costa; CUNHA MASCENA, Keysa Manuela. Análise de competitividade em clusters de negócio: uma consolidação de parâmetros. Redes (St. Cruz Sul, Online), Santa Cruz do Sul, v. 25, n. 2, p. 610-634, maio 2020. ISSN 1982-6745. Disponível em: https://online.unisc.br/seer/index.php/redes/article/view/13226 Acesso em: 15 maio 2020. doi: https://doi.org/10.17058/redes.v25i2.13226

\section{CONTRIBUIÇÃO DE CADA AUTOR}

a. Fundamentação teórico-conceitual e problematização: Azevedo e Pereira.

b. Pesquisa de dados e análise estatística: Azevedo, Pereira e Mascena.

c. Elaboração de figuras e tabelas: Azevedo e Pereira.

d. Fotos: Não se aplica.

e. Elaboração e redação do texto: Azevedo, Pereira e Mascena.

f. Seleção das referências bibliográficas: Azevedo e Pereira.

Fontes de financiamento:

O presente trabalho foi realizado com apoio da Coordenação de Aperfeiçoamento de Pessoal de Nível Superior - Brasil (CAPES) - Código de Financiamento 001. 